\title{
Adjuvant effects of classical music on simvastatin induced reduction of anxiety but not object recognition memory in
}

\section{rats}

\author{
Anice Milbratz de Camargo ${ }^{1}$, Daniela Delwing de Lima ${ }^{2}$, Débora Delwing Dal Magro ${ }^{1}$, Johanna \\ Kleis Seubert ${ }^{1}$, Júlia Niehues da $\mathrm{Cruz}^{3}$, and José Geraldo Pereira da Cruz ${ }^{1}$ \\ 1. Universidade Regional de Blumenau, Blumenau, SC, Brazil \\ 2. Universidade da Região de Joinville, Joinville, SC, Brazil \\ 3. Universidade do Extremo Sul Catarinense, Criciúma, SC, Brazil
}

\begin{abstract}
Simvastatin is one of many hydroxymethylglutaryl-coenzyme-A reductase inhibitors that are prescribed to lower cholesterol. Some emerging evidence indicates that classical music can serve as an effective adjuvant in rats treated with simvastatin. Moreover, simvastatin and classical music have been shown to influence some cognitive functions. To further understand the mechanisms of action, we exposed rats to classical music for 1 month, and then treated them orally with simvastatin. The behavioral experiments suggested that exposure to subchronic simvastatin ( 1 or $10 \mathrm{mg} / \mathrm{kg} /$ day $)$ reduced anxiety levels in the elevated plus-maze and open-field test in rats exposed to Mozart music. The recognition object test results indicated that simvastatin altered non-spatial working memory only at the $1 \mathrm{mg} / \mathrm{kg}$ /day dose and improved both short- and long-term object recognition. No significant differences were found between Mozart music and silence in the object recognition test, suggesting that music did not significant affect learning and memory in adult rats. We hypothesize that the anxiolytic, but not object-recognition memory, effects of simvastatin and classical music occur through similar mechanisms, providing an important foundation for future preclinical and clinical research. Keywords: anxiety, elevated plus-maze, music, object recognition, open-field, simvastatin.
\end{abstract}

Received 18 September 2012; received in revised form 22 July 2013; accepted 24 July 2013. Available online 23 December 2013.

\section{Introduction}

Simvastatin has been widely used clinically to reduce serum low-density lipoprotein (LDL) cholesterol by inhibiting the rate-limiting enzyme, hydroxymethylglutaryl-coenzyme reductase. The neuroprotective effects of statins have also been suggested in several studies. Compared with other statins, simvastatin is more lipophilic and more easily permeates the blood-brain barrier, which could offer a further neuroprotective effects (Hayashi et al., 2005; Sierra, Ramos, Molina, Esteo, Vázquez, \& Burgos, 2011; Urban et al., 2009). Additionally, evidence

Anice Milbratz de Camargo, Débora Delwing Dal Magro, Johanna Kleis Seubert, and José Geraldo Pereira da Cruz, Departamento de Ciências Naturais, Universidade Regional de Blumenau, Blumenau, SC, Brazil. Daniela Delwing de Lima, Departamento de Farmácia, Universidade da Região de Joinville, Joinville, SC, Brazil. Júlia Niehues da Cruz, Departamento de Medicina, Universidade do Extremo Sul Catarinense, Criciúma, SC, Brazil. Correspondence regarding this article should be directed to: José Geraldo Pereira da Cruz, Departamento de Ciências Naturais, Universidade Regional de Blumenau, Rua Antônio da Veiga, 140, Blumenau, 89012900, Santa Catarina, Brazil; Phone: +55 0473321 0272; Fax: +5504733210233; E-mail: jgcruz@furb.br indicates that simvastatin reduces the risk of ischemic heart disease and cerebrovascular stroke, with potential applications in multiple sclerosis, traumatic brain injury, Alzheimer's disease, and anxiety and potential effects on cognition (Baytan et al., 2008, Carrocini et al., 2012; Sett, Robinson, \& Mistri, 2011; Swindle, Potash, Kulakodlu, Kuznik, \& Buikema, 2011; Tramontina et al., 2011; Wang et al., 2009; Zhang, Tao, Troiani, \& Markovic-Plese, 2011). Despite growing evidence of the role of simvastatin in central nervous system diseases, relatively little knowledge is available about its direct neuropsychological effects on central receptors and association with anxiolytic-like behavioral effects and cognitive decline associated with neurodegenerative diseases (Carrocini et al., 2012; Jukema, Cannon, de Craen, Westendorp, \& Trompet, 2012).

Clinical reports indicate that music can be an effective treatment for numerous disorders. Music therapy has shown promising results for cognition. It has also been shown to be useful as an adjunct therapy for addiction and for the treatment of anxiety, chronic stress, pain, sleep disorders, autism, depression, psychosis, and posttraumatic stress disorder (Bernatzky, Presch, Anderson, \& Panksepp, 2011; Chan, Chan, \& Mok, 
2010; Chan,Wong, \& Thayala, 2011; Cruz, Dal Magro, \& Cruz, 2010; Gold, Solli, Krüger, \& Lie, 2009; Polston, Rubbinaccio, Morra, Sell, \& Glick, 2011; Raglio et al., 2012; Wan, Demaine, Zipse, Norton, \& Schlaug, 2010). Music can enhance medical therapies and be used as an adjuvant with other anxiety-management programs to increase the effectiveness of those therapies (Raglio et al., 2012). However, although musical appreciation is well documented in the human population, significant disagreement still exists in the literature about whether this is confined to the human species or extends to other members of the animal kingdom. Considering the enormous potential that music therapy offers, a growing need exists to develop preclinical models.

Research conducted in our laboratory suggests that subchronic simvastatin treatment reduces anxiety levels in rats when associated with Mozart music. Our study the first to show that is statins combined with music have anxiolytic-like effects in the elevated plus-maze (Cruz, Lima, Dal Magro, \& Cruz, 2011). A possible mechanism of action for these effects may involve the modulation of N-methyl-D-aspartate (NMDA) receptors (Wang et al., 2009; Xu, Yu, Cai, Zhang, \& Sun, 2009; Yan et al., 2011). These results indicate that music can serve as an effective adjuvant in rats treated with simvastatin, and this species may potentially be used in other preclinical models that utilize musical interventions. Additionally, the mechanisms by which simvastatin and music exert their beneficial effects may be related to the modulation of the signaling pathways involved in memory formation. Surprisingly, a relative paucity of such preclinical studies is available, particularly with regard to anxiety and memory.

The present study sought to confirm and extend these findings. We examined the effects of Mozart music combined with simvastatin in rats using a range of behavioral paradigms. A battery of two different anxiety tests was used for the first paradigm, which is thought to reflect anxiety states in humans. These consisted of: the elevated plus-maze (Pellow, Chopin, File, \& Briley, 1985) and open-field test (Prut \& Belzung, 2003). To assess memory, the novel object recognition test was used. This model is thought to measure non-spatial working memory in rats (Ennaceur, 2010).

\section{Methods}

\section{Subjects}

A total of 60 male genetically heterogeneous albino Wistar rats (Rattus norvegicus), 3 to 5 months and weighing 220 to $310 \mathrm{~g}$, were obtained from the animal house of the Regional University of Blumenau. After arrival in the vivarium of the laboratory, these animals were housed in groups of five per opaque plastic cage $(50 \times 30 \times 15 \mathrm{~cm})$ with wood shaving bedding and wire mesh tops. They were housed under a standard $(12 \mathrm{~h} / 12 \mathrm{~h}$ light/dark; cycle lights on at 7:00 AM), in a temperature-controlled environment $\left(23 \pm 1^{\circ} \mathrm{C}\right)$, with a $50 \mathrm{~dB}$ background sound level, and $55 \pm 10 \%$ relative humidity. During the light and dark phases, the rats were exposed to light intensities of approximately 500 and 0,025 lux, respectively. These lux values were chosen because they were the light intensities that were closest to natural daytime and nighttime light in our laboratory. During the entire experimental period, the animals received commercial chow for rodents (Nuvital, Paraná, Brazil) and filtered tap water ad libitum. At irregular intervals the room was visited an average of once every 2 or 3 days clean the cages, and provide food and water. The animals were acclimated to the animal housing facilities for at least 1 week before the experiments began. The experiments were performed in compliance with the recommendations of the Brazilian Society of Neuroscience and Behavior (SBNeC), which are based on the United States National Institutes of Health Guide for Care and Use of Laboratory Animals.

\section{Experimental protocols}

The rats were divided into two groups: silence and music. They were randomized with 10 rats per group and orally received either simvastatin ( 1 or $10 \mathrm{mg} / \mathrm{kg}$ / day by oral gavage, Zocor; Merck KGaA, Darmstadt, Germany) or saline, control group, for 4 consecutive weeks. The rats in the auditory enriched conditions were exposed to music for $5 \mathrm{~h} /$ day, between 12:00 and 5:00 PM. The music (i.e., Mozart's piano sonata, KV361, Largo, 8:35 min duration) was continuous and repeated on a compact disc player (Cruz et al., 2010). The speaker had a frequency range of 100-16000 Hz. The silent room was exactly the same as the room in which music was played but no sound was made, with the exception of ambient noises such as those produced by the air conditioner. The sound levels for the silence and music groups were $50 \mathrm{~dB}$ (ambient noise) and 65$75 \mathrm{~dB}$, respectively, in the home cages and behavioral apparatus. After 4 weeks the rats in each subgroup were selected for the behavioral studies.

\section{Behavioral tests}

The animals were individually subjected to the elevated plus-maze, open-field test and object recognition test. All of the behavioral procedures were conducted during the light phase (between 1:00 and 4:00 PM), in a sound-isolated room, when the rodents were less active. To minimize possible circadian influences, the experimental and control observations were alternated. The observer stayed in the same room, approximately $1 \mathrm{~m}$ away from the apparatus (Ennaceur, 2010; Pellow et al., 1985; Prut \& Belzung, 2003). The tests were conducted under dim red light (44 lux).

\section{Elevated plus-maze test}

The apparatus consisted of two open arms $(50 \times 10$ $\mathrm{cm})$ and two closed arms $(50 \times 10 \times 40 \mathrm{~cm})$ arranged such that the two arms of each type were opposite to each other, with a central platform $(10 \times 10 \mathrm{~cm})$. The height of the maze was $50 \mathrm{~cm}$. The animals were exposed for 5 min to the red light in their own home cages before the 
testing procedure. They were then individually placed on the central platform of the elevated plus-maze facing an open arm. During a 5 min test period the following parameters were recorded by an observer: time spent on the open arms, number of entries into the open arms, time spent on the closed arms, number of entries into the closed arms and risk assessment (Pellow et al., 1985). Risk assessment is a measure that accounts for the time spent head-dipping (i.e., exploratory movements of the head/and shoulders over the side of the maze) and in a stretched attend posture (i.e., exploratory posture in which the body is stretched forward and then retracted to the original position without any forward locomotion). The measures that reflect anxiety-like behavior in this test are the entries into the open arms vs. closed arms and time spent on the open arms vs. closed arms. We also included ethologically derived measures related to the defensive pattern of risk assessment behavior, which has been shown to be very sensitive to changes in anxiety.

\section{Open-field test}

The open-field consisted of a black circular box (60 $\mathrm{cm}$ diameter, $50 \mathrm{~cm}$ height). Each rat was placed in the central area and allowed to freely explore the apparatus for $5 \mathrm{~min}$. Every time both hind paws entered one square, a crossing was recorded. The total distance traveled by the animals was estimated by the number of squares crossed. Ambulation time (i.e., movement from one location to another), the time spent immobile (i.e., completely immobile), the time spent rearing (the rat stood on its hind paws with its body at greater than a $45^{\circ}$ angle to the floor) and the time spent grooming (i.e., repetitive movements of the front paws or mouth on the fur) were also recorded (Prut \& Belzung, 2003).

\section{Object recognition test}

The object recognition test measures non-spatial working memory in rats and takes advantage of the unprompted nature of rats to explore their surroundings (Ennaceur, 2010). This model is advantageous because it does not require punishment or reward and is quick and simple to implement. The rats were first exposed to two identical objects. After a specific delay, the rat was then presented with one of the familiar objects and a novel object. When a rat "remembers" the previous exposure to the familiar object, it will explore the novel object to a greater extent than the familiar one. All of the animals were habituated to the experimental arena in the absence of any specific behavioral stimulus for $20 \mathrm{~min} /$ day for 4 days. The objects, were made of metal or glass, and affixed to the arena's floor with adhesive tape. In the pretest two identical objects ( $\mathrm{M}$ and $\mathrm{N}$ ) were placed in the corners of the box. The test was repeated $2 \mathrm{~h}$ later to valuate short-term memory or $24 \mathrm{~h}$ later to evaluate long-term memory after the pretest. In the tests, one of the objects was changed for a new object ( $\mathrm{P}$ for short-term memory; $\mathrm{R}$ for long-term memory). The time allowed for exploration in each trial was 5 min. The positions of the objects (familiar or novel) were randomly permuted for each experimental animal and the arena was cleaned between trials. Exploration was defined as sniffing or touching the object with the nose or forepaws. Sitting on or turning the object was not considered exploratory behavior. The time spent exploring each object was recorded by an observer who was blind to treatment and is expressed as total exploration time (in seconds).

\section{Statistical analysis}

All of the data are expressed as \pm S.E.M. Each value reflects the mean of 10 animals per group. The means were compared using analysis of variance (ANOVA), followed by the Newman-Keuls multiple comparison test. A probability level of .05 was used as the criterion for statistical significance.

\section{Results}

The ANOVA revealed significant differences between subgroups in the time spent on the open arms of the elevated plus-maze $(\mathrm{F}=4.160 ; \mathrm{p}<.01)$. Musicexposed rats that received simvastatin (1 or $10 \mathrm{mg} / \mathrm{kg}$ ) exhibited an increased time spent on the open arms compared with the silence $/ 0 \mathrm{mg} / \mathrm{kg}$ simvastatin $(\mathrm{p}<$ .05 , Figure 1A). However, no significant difference was observed between groups in the time spent the closed $\operatorname{arms}(\mathrm{F}=.7562 ; \mathrm{p}>.05$; Figure 1B). Music exposure significantly increased the number of open arm entries in rats that received 1 or $10 \mathrm{mg} / \mathrm{kg}$ simvastatin compared with the silence $/ 0 \mathrm{mg} / \mathrm{kg}$ simvastatin $(\mathrm{F}=5.483 ; \mathrm{p}<$ .001 and $\mathrm{p}<.01$; respectively; Figure $1 \mathrm{C}$ ). No significant difference was found between groups, in the number of closed arm entries $(\mathrm{F}=.9901 ; \mathrm{p}>.05$; Figure 1D) or risk assessment $(\mathrm{F}=1.275 ; \mathrm{p}>.05$; Figure 1E).

The ANOVA revealed significant differences between groups ambulation time in the open-field ( $\mathrm{F}$ $=8.350 ; \mathrm{p}<.001)$. Music-exposed rats that received simvastatin (1 or $10 \mathrm{mg} / \mathrm{kg}$ ) exhibited an increased ambulation time compared with the silence $/ 0 \mathrm{mg} / \mathrm{kg}$ simvastatin group $(\mathrm{p}<.01$ and $\mathrm{p}<.001$; respectively; Figure 2A). Additionally, music exposure significantly increased the distance traveled at simvastatin doses of 1 and $10 \mathrm{mg} / \mathrm{kg}(\mathrm{F}=4.052 ; \mathrm{p}<.05$; Figure $2 \mathrm{~B})$ and decreased the time spent immobile $(\mathrm{F}=6.195 ; \mathrm{p}<.05$ and $\mathrm{p}<.01$; respectively; Figure $2 \mathrm{C}$ ). No significant difference was found between groups, in the time spent rearing $(\mathrm{F}=1.680 ; \mathrm{p}>.05$; Figure $2 \mathrm{D})$ or time spent grooming $(\mathrm{F}=1.146 ; \mathrm{p}>.05$; Figure $2 \mathrm{E})$.

The ANOVA revealed a significant enhancement of non-spatial learning in the object recognition test. Rats in the silence group $(\mathrm{F}=3.916 ; \mathrm{p}<.01)$ and musicexposed group $(\mathrm{F}=4.804 ; \mathrm{p}<.01)$, that received $1 \mathrm{mg} /$ $\mathrm{kg}$ simvastatin, exhibited improvements in both shortterm and long-term object recognition memory $(\mathrm{p}<$ .05; Figure 3A and B). However, in the silence group that received saline $(\mathrm{F}=.1476 ; \mathrm{p}>.05)$ or $10 \mathrm{mg} / \mathrm{kg}$ simvastatin $(\mathrm{F}=1.690 ; \mathrm{p}>.05)$, as well as the group music treated with saline $(\mathrm{F}=0.3299 ; \mathrm{p}>0,05)$ or 10 

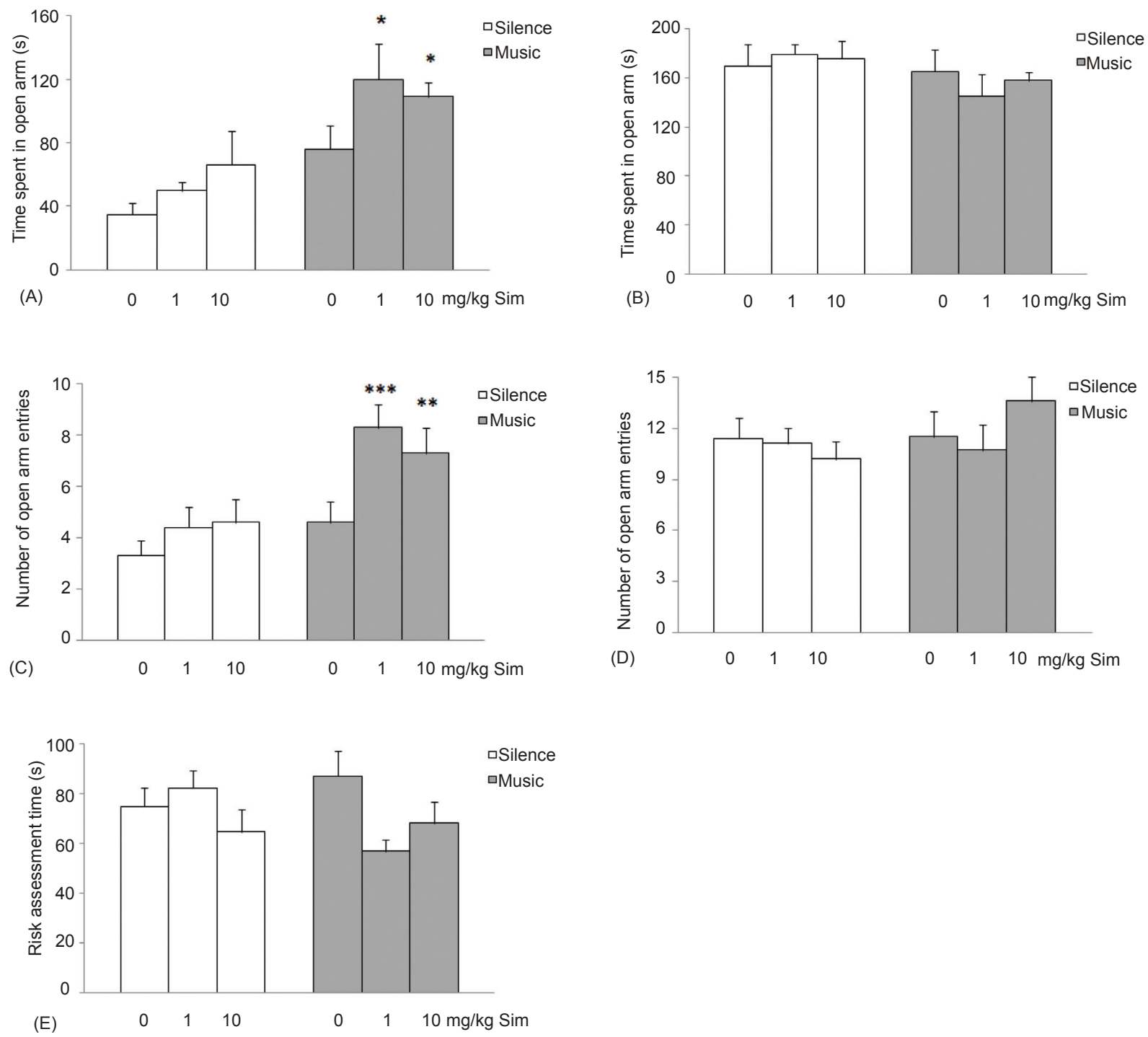

Figure 1. Effect of simvastatin (1 and $10 \mathrm{mg} / \mathrm{kg} / \mathrm{day}$ ) on anxiety-like behavior in rats under each sound condition (silence and music) in the elevated plus-maze. (A) Time spent on the open arms. (B) Time spent on the closed arms. (C) Number of open arm entries. (D) Number of closed arm entries. (E) Risk assessment. The data are expressed as mean $\pm \operatorname{SEM}\left(\mathrm{n}=10 /\right.$ group). ${ }^{*} \mathrm{p}<.05$, $* * \mathrm{p}<.01, * * * \mathrm{p}<.001$ (ANOVA followed by Newman-Keuls test).

$\mathrm{mg} / \mathrm{kg}$ simvastatin $(\mathrm{F}=2.421 ; \mathrm{p}>.05)$, exhibited no alterations in short- or long-term memory.

\section{Discussion}

The present results suggest that subchronic treatment with simvastatin reduced anxiety levels in rats when associated with Mozart music. Music exposure combined with simvastatin increased the time spent on the open arms and entries into the open arms of the elevated plus-maze (Figure 1). An increased time spent on the open arms and entries into the open arms of the elevated plus-maze are interpreted as a reduction of anxiety-like behavior (Pellow et al., 1985). The differences in anxiotypic behavior expressed by these animals are not limited to their performance on the elevated plus-maze. A novel environment is used to establish general anxiotypic behavior, and levels of locomotion in this paradigm can be used as indices of an anxiety-like state in rats (Prut \& Belzung, 2003). Music combined with 1 or $10 \mathrm{mg} / \mathrm{kg}$ simvastatin increased ambulation time and the distance traveled and reduced the time spent immobile in the open-field (Figure 2), indicating increased exploratory activity.

This result is consistent with other studies in which male Wistar rats that were subcronically treated with the same doses of simvastatin exhibited a reduction of anxiety when associated with Mozart music, exposure $24 \mathrm{~h}$ before the behavioral tests (Cruz et al., 2011). Several physiological mechanisms have been suggested to explain the beneficial effects of simvastatin on anxiety (Wang et al., 2009; Yan et al., 2011). A possible mechanism that mediates these effects may involve the modulation of NMDA receptors in Sprague-Dawley rats (Wang et al., 2009; Xu et al., 2009; Yan et al., 

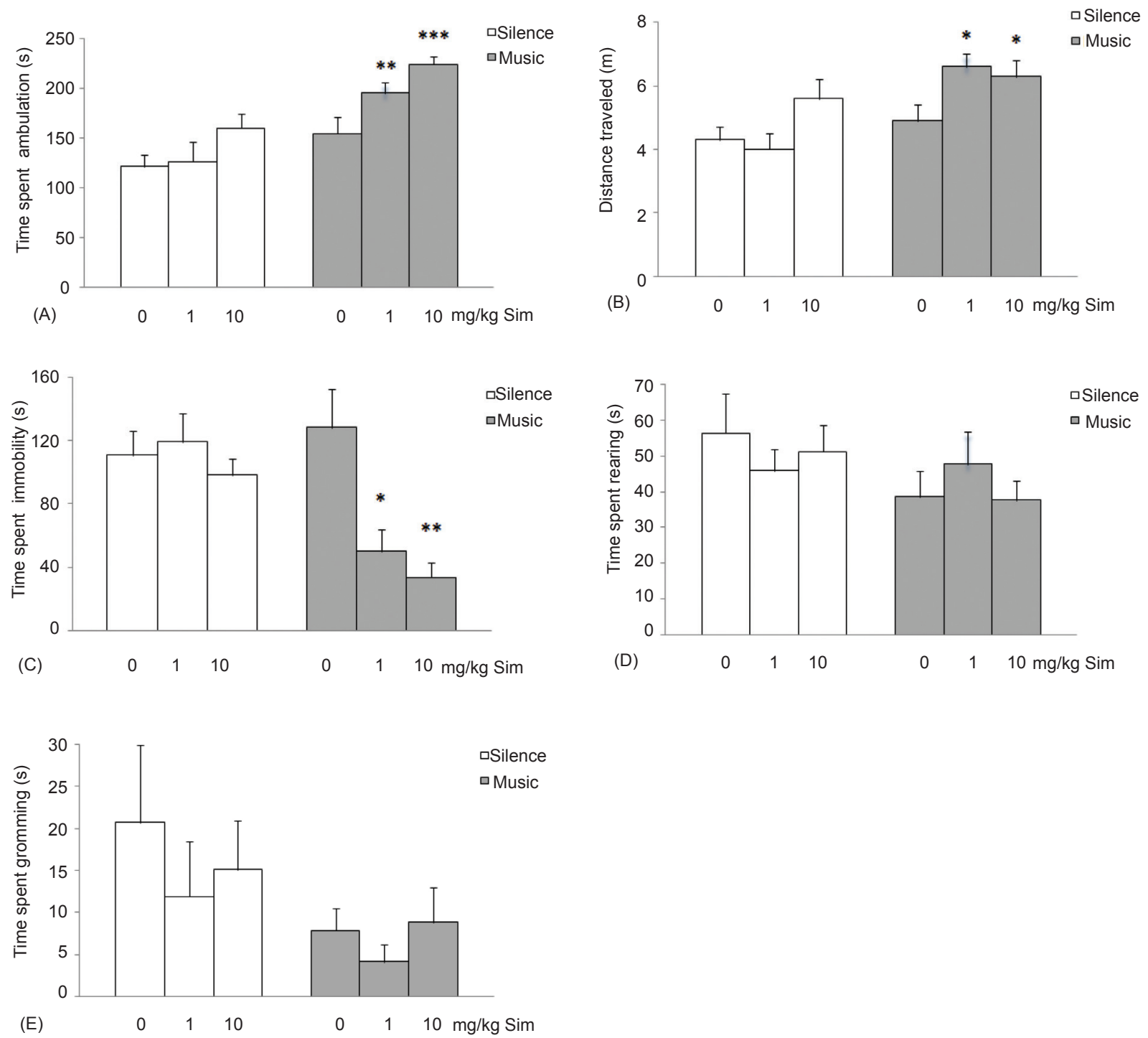

Figure 2. Effect of simvastatin ( 1 or $10 \mathrm{mg} / \mathrm{kg} / \mathrm{day}$ ) on locomotor activity and exploratory behavior of rats under each sound conditions (silence or music) in the open-field test. (A) Ambulation time. (B) Distance traveled. (C) Time spent immobile. (D) Time spent rearing. (E) Time spent grooming. The data are expressed as mean $\pm \mathrm{SEM}\left(\mathrm{n}=10 /\right.$ group). ${ }^{*} \mathrm{p}<.05,{ }^{*} \mathrm{p}<.01,{ }^{* * *} \mathrm{p}<$ .001 (ANOVA followed by Newman-Keuls test).
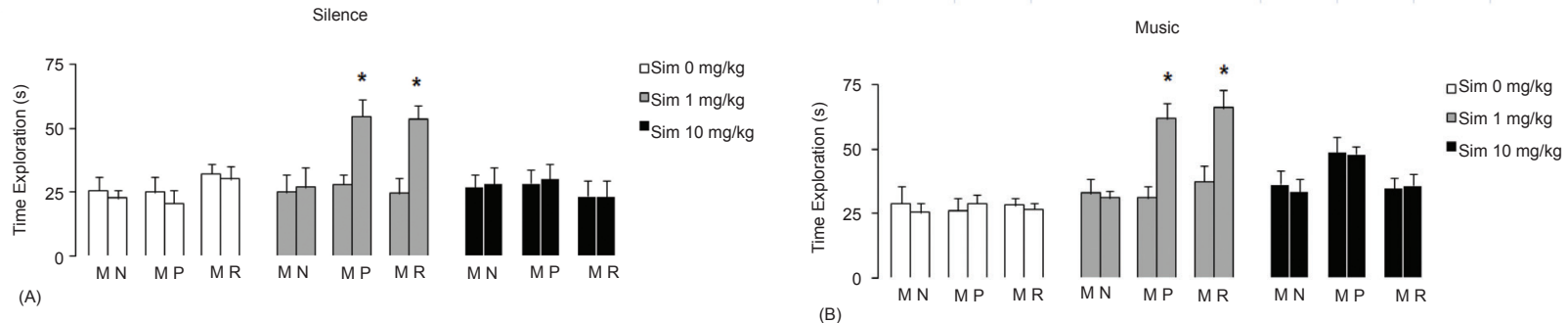

Figure 3. Effect of simvastatin (1 or $10 \mathrm{mg} / \mathrm{kg} /$ day) on learning and memory in rats under each sound conditions (silence or music) in the object recognition test. (A) Exploration time in silence group. (B) Exploration time in music group. The rats were exposed to two identical objects $(\mathrm{M}$ and $\mathrm{N})$ in the pretest session. Two hours later, a short-tem memory (STM) test was performed, in which the animals were exposed to a familiar object $(\mathrm{M})$ and a novel object $(\mathrm{P})$. Long-term memory (LTM) was assessed $24 \mathrm{~h}$ after pretest, in which the animals were exposed again to the familiar object $(\mathrm{M})$ and to another novel object (R). The data are expressed as mean \pm SEM $\left(n=10\right.$ /group). ${ }^{*} \mathrm{p}<.05$, significant difference between groups (Newman-Keuls test). 
2011). Another possible mechanism may involve the modulation of cholesterol distribution within brain cell membranes (Kirsch, Eckert, \& Mueller, 2003). Because of the relatively high concentration of cholesterol in the brain, the detection of changes that are specific to membrane cholesterol is difficult. However, evidence indicates that chronic simvastatin administration does not change cholesterol levels in brain tissue or plasma in rodents (Mok et al., 2006; Wang et al., 2009). The effects of simvastatin in central nervous system may be hypothesized to occur via a central mechanism that is independent of hypocholesterolemic properties (Johnson-Anuna et al., 2005; Schoonjans, PeinadoOnsurbe, Fruchart, Tailleux, Fiévet, \& Auwerx, 1999).

The literature is inconsistent with regard to whether animals "appreciate" music, but such a determination is not necessary for the utilization of music in animal models of anxiety. In fact, it may prove to be advantageous if the subjects do not experience pleasure from the music alone, because this would further complicate analyses and interpretations. Although the hearing range of rats and humans is different, 1-100 $\mathrm{kHz}$ and $20 \mathrm{~Hz}$ to $20 \mathrm{kHz}$, respectively, we found that music created for humans can also lead to behavioral changes in rats (Heffner \& Heffner, 2007). Rats are able to discriminate musical passages, processing of melodic contour and speaker variability in phonetic boundaries (Otsuka, Yanagi, \& Watanabe, 2009; Ruusuvirta, Koivisto, Wikgren, \& Astikainen, 2007; Toro, Trobalon, \& Sebastián-Gallés, 2005). However, unknown are the specific features of music, such as timbre, tempo, key, modulating frequency, rhythm, or some combination thereof, that are integral to its efficacy in rats. Additionally, complex acoustic stimuli engage multiple brain regions beyond primary sensory areas, including centers for arousal, emotion, and reward (Blood \& Zatorre, 2001). However, our goal was not to determine whether rats have an appreciation for Mozart; instead, we sought to determine whether a complex musical passage can be effectively used as an adjuvant anxiolytic in rats treated with simvastatin in the elevated plus-maze and open-field test.

Pleasurable music evokes neurological responses that are similar to the effects induced by anxiolytic drugs. Specifically, highly enjoyable music and simvastatin induce cerebral activation in anxiety-related brain regions, such as the amygdala (Blood \& Zatorre, 2001; Yan et al., 2011). The amygdala has been linked to many functional systems in the mammalian brain, including neuromodulatory, autonomic, endocrine, limbic, and neocortical circuits. Because of the anatomical position of the amygdala and its extensive reciprocal and diverse neural projections, it serves as a hub of sensory affective neurotransmission. Furthermore, the amygdala performs concatenate functions that facilitate communication between sensory encoding, interpretative systems, motor planning, and determination pathways (Balleine $\&$ Killcross, 2006). Decades of research have implicated the amygdala as the neural substrate responsible for regulating and modifying behaviors in an adaptive manner that favors the most advantageous outcomes possible. Therefore, the anxiolytic effects likely result from positive emotional experiences elicited by pairing simvastatin administration with music. Emotionrelated behavioral responding can be viewed as the coordinated processing of amygdaloid nuclei. The basolateral amygdala encodes and retrieves the affective value of environmental stimuli, and directs complex adaptive behavioral responses to an older central amygdala system that enables cortical structures to recruit incentive motivational processes and invigorate emotional responding (Everitt, Cardinal, Parkinson, \& Robbins, 2003).

We were interested in determining the effects of simvastatin combined with classical music on non-spatial learning. Testing this aspect of exploratory behavior allowed to further characterize the possible effects of simvastatin and Mozart music on responses to novelty. Our results showed that simvastatin influenced learning and memory processes independently of Mozart music. The object recognition test indicated that simvastatin altered non-spatial working memory in Wistar rats only at the $1 \mathrm{mg} / \mathrm{kg} /$ day dose and improved both short- and longterm object recognition memory (Figure 3 ). However, no significant differences were found between Mozart music and silence in the object recognition test, suggesting that music did not significantly affect learning and memory in adult rats.

Numerous studies reported that statins improved cognition in mice (Li, Cao, Kim, Lester, \& Fukuchi. 2006), possibly by modulating of signaling pathways implicated in synaptic plasticity and spatial memory formation (Vaughan, 2003). Notably, increased levels of NMDA receptors following chronic simvastatin treatment have been reported in rats (Wang et al. 2009). Additionally, we reported that treating hippocampal slices with simvastatin for several hours increased the magnitude of NMDA receptor-dependent long-term potentiation, a mechanism that is thought to mediate memory at the cellular level, in the CA1 region in young adult C57BL/6 mice (Mans, Chowdhury, Cao, McMahon, \& Li, 2010).

Object recognition memory, depends on the perirhinal cortex. Whether it is a hippocampus or nonhippocampus-dependent task is still debatable. Some studies reported that the task does not require the hippocampus, but several studies support the hypothesis that the hippocampus contributes to learned object familiarity (Mumby, Glenn, Nesbitt, \& Kyriazis, 2002; Roecker et al., 2012).

NMDA receptors play an important role in learning and memory (Magnusson \& Cotman, 1993). Neurogenesis in the dentate gyrus (Lu et al., 2007), angiogenesis (Pooler, Xi, \& Wurtman, 2006) and brain-derived neurotrophic factor production $(\mathrm{Wu}$ et al., 2008) are stimulated by chronic statin treatment. Statins have been used clinically to ameliorate cognitive deficits in different neurodegenerative disorders such as 
Parkinson's disease, Alzheimer's disease and vascular dementia (Cramer, Haan, Galea, Langa, \& Kalbfleisch, 2008; Carlsson et al., 2008). The cumulative reduction of anxiety in patients occurs independently of the cholesterol-lowering effect of statins (Young-Xu, Chan, Liao, Ravid, \& Blatt, 2003). However, more scientific investigations, both preclinical and clinical are needed to specifically determine the effects of statins on cognition.

Several important clinical implications emerged with the finding that simvastatin augmented the behavioral effects of classical music in the elevated plus-maze and open-field test. The anxiolytic-like behavioral effects of simvastatin combined with Mozart music indicated that the neural circuitry associated with these effects may be similar. The conceptual hypothesis that simvastatin and music produce behavioral effects through similar mechanisms provides an important direction for future clinical research. For example, the results suggest that simvastatin, similar to NMDA antagonists, combined with classical music possesses anxiolytic effects in preclinical tests that predict of clinical efficacy. This is particularly relevant for anxiolytic treatment in benzodiazepine-resistant patients who develop hypocholesterolemia (Cruz et al., 2012; Carrocini et al., 2012; Santos et al., 2012).

Recently, much attention has been devoted to the glutamatergic system and NMDA receptor antagonists in particular (RiazaBermudo-Soriano, Perez-Rodriguez, Vaquero-Lorenzo, \& Baca-Garcia, 2012). The results of these studies may be important for continuing to distinguish the preclinical and clinical behavioral effects of different types of anxiolytic drugs. This may suggest that our efforts should be shifted to the pursuit of new glutamatergic (or other alternative) compounds rather than remaining on the well-trodden path of aminobutyric acid-ergic drug development if we hope to identify truly novel drugs with unique and improved therapeutic profiles.

In summary, the present results strongly indicate that simvastatin combined with classical music improved coping with aversive situations, leading to a reduction of anxiety and indicating a synergistic effect of combination therapy. However, our results showed that simvastatin influenced learning and memory processes independently of Mozart music. The present study indicates that simvastatin combined with classical music may have sufficient construct, face, and predictive validity to become an interesting "pathological" model for pharmacotherapeutic approaches to the treatment of anxiety-like disturbances supporting the view that statins may prevent or improve cognitive decline in animals and humans.

\section{Competing Interests}

The authors declare that they do not have any financial or nonfinancial competing interests.

\section{References}

Balleine, B. W., \& Killcross, S. (2006). Parallel incentive processing: an integrated view of amygdala function. Trends in Neurosciences, $29,272-279$.
Baytan, S. H., Alkanat, M., Okuyan, M., Ekinci, M., Gedikli, E., Ozeren, M., \& Akgun A. (2008). Simvastatin impairs spatial memory in rats at a specific dose level. Tohoku Journal of Experimental Medicine, 214, 341-349.

Bernatzky, G., Presch, M., Anderson, M., \& Panksepp, J. (2011). Emotional foundations of music as a non-pharmacological pain management tool in modern medicine. Neuroscience and Biobehavioral Reviews, 35, 1989-1999.

Blood, A. J., \& Zatorre, R. J. (2001). Intensely pleasurable responses to music correlate with activity in brain regions implicated in reward and emotion. Proceedings of the National Academy of Sciences of the United States of America, 98, 11818-11823.

Carlsson, C. M., Gleason, C. E., Hess, T. M., Moreland, K. A., Blazel, H. M., Koscik, R. L., Schreiber, N. T., Johnson, S. C., Atwood, C. S., Puglielli, L., Hermann, B. P., McBride, P. E., Stein, J. H., Sager, M. A., \& Asthana, S. (2008). Effects of simvastatin on cerebrospinal fluid biomarkers and cognition in middle-aged adults at risk for Alzheimer's disease. Journal of Alzheimer's Disease, 13, 187-197.

Carrocini, M. S., Caxambú, A. L., Kelle, N. S., de Lima, D. D., Cruz, J. N., Dal Magro, D. D., \& Cruz, J. G. (2012). Chronic simvastatin treatments attenuate ethanol withdrawal syndrome in rats. American Journal of Medicine and Medical Sciences, 2, 22-28.

Chan, M. F., Chan, E. A., \& Mok, E. (2010). Effects of music on depression and sleep quality in elderly people: a randomised controlled trial. Complementary Therapies in Medicine, 18, 150-159.

Chan, M. F., Wong, Z. Y., \& Thayala, N. V. (2011). The effectiveness of music listening in reducing depressive symptoms in adults: a systematic review. Complementary Therapies in Medicine, 19, 332-348.

Cramer, C., Haan, M. N., Galea, S., Langa, K. M., \& Kalbfleisch, J. D. (2008). Use of statins and incidence of dementia and cognitive impairment without dementia in a cohort study. Neurology, 71, 344-350.

Cruz, J. G., Dal Magro, D. D., \& Cruz, J. N. (2010). Effects of classic music as part of environmental enrichment in captive Mus musculus (Rodentia: Muridae). Biotemas, 23, 191-197.

Cruz, J. N., Lima, D. D., Dal Magro, D. D., \& Cruz, J. G. P. (2011). The power of classic music to reduce anxiety in rats treated with simvastatin. Basic and Clinical Neurocience, 2, 5-11.

Cruz, J. N., Tomasi, C. D., Alves, S. C., Macedo, R. C., Giombelli, V., Cruz, J. G., Dal-Pizzol, F., \& Ritter, C. (2012). The incidence of delirium in patients pretreated with statins who remain in an intensive care unit after cardiac surgery. Revista Brasileira de Terapia Intensiva, 24, 52-57.

Ennaceur, A. (2010). One-trial object recognition in rats and mice: methodological and theoretical issues. Behavioural Brain Research, 215, 244-254.

Everitt, B. J., Cardinal, R. N., Parkinson, J. A., \& Robbins, T. W. (2003). Appetitive behavior: impact of amygdala-dependent mechanisms of emotional learning. Annals of the New York Academy of Sciences, 985, 233-250.

Gold, C., Solli, H. P., Krüger, V., \& Lie, S. A. (2009). Doseresponse relationship in music therapy for people with serious mental disorders: systematic review and meta-analysis. Clinical Psychology Review, 29, 193-207.

Heffner, H. E., \& Heffner, R. S. (2007). Hearing ranges of laboratory animals. Journal of the American Association for Laboratory Animal Science, 46, 20-22.

Hayashi, T., Hamakawa, K., Nagotani, S., Jin, G., Li, F., Deguchi, K., Sehara, Y., Zhang, H., Nagano, I., Shoji, M., \& Abe, K. (2005). HMG CoA reductase inhibitors reduce ischemic brain injury of Wistar rats through decreasing oxidative stress on neurons. Brain Research, 1037, 52-58.

Johnson-Anuna, L. N., Eckert, G. P., Keller, J. H., Igbavboa, U., Franke, C., Fechner, T., Schubert-Zsilavecz, M., Karas, M., Müller, W. E., \& Wood, W. G. (2005). Chronic administration of statins alters multiple gene expression patterns in mouse cerebral cortex. Journal of Pharmacology and Experimental Therapeutics, 312, 786-793.

Jukema, J. W., Cannon, C. P., de Craen, A. J., Westendorp, R. G., \& Trompet, S. (2012). The controversies of statin therapy: weighing the evidence. Journal of the American College of Cardiology, 60, 875-881. 
Kirsch, C., Eckert, G. P., \& Mueller, W. E. (2003). Statin effects on cholesterol micro-domains in brain plasma membranes. Biochemical Pharmacology, 65, 843-856.

Li, L., Cao, D., Kim, H., Lester, R., \& Fukuchi, K. (2006). Simvastatin enhances learning and memory independent of amyloid load in mice. Annals of Neurology, 60, 729-739.

Lu, D., Qu, C., Goussev, A., Jiang, H., Lu, C., Schallert, T., Mahmood, A., Chen, J., Li, Y., \& Chopp, M. (2007). Statins increase neurogenesis in the dentate gyrus, reduce delayed neuronal death in the hippocampal CA3 region, and improve spatial learning in rat after traumatic brain injury. Journal of Neurotrauma, 24, 11321146

Magnusson, K. R., \& Cotman, C. W. (1993). Effects of aging on NMDA and MK801 binding sites in mice. Brain Research, 604, 334-337.

Mans, R. A., Chowdhury, N., Cao, D., McMahon, L. L., \& Li, L. (2010). Simvastatin enhances hippocampal long-term potentiation in C57BL/6 mice. Neuroscience, 166, 435-444.

Mok, S. W., Thelen, K. M., Riemer, C., Bamme, T., Gultner, S., Lutjohann, D., \& Baier, M. (2006). Simvastatin prolongs survival times in prion infections of the central nervous system. Biochemical and Biophysical Research Communications, 348, 697-702.

Mumby, D. G., Gaskin, S., Glenn, M. J., Schramek, T. E., \& Lehmann, H. (2002). Hippocampal damage and exploratory preferences in rats: memory for objects, places, and contexts. Learning \& Memory, 9, 49-57.

Otsuka, Y., Yanagi, J., \& Watanabe, S. (2009). Discriminative and reinforcing stimulus properties of music for rats. Behavioural Processes, 80, 121-127.

Pellow, S., Chopin, P., File, S. E., \& Briley, M. (1985). Validation of open: closed arm entries in the elevated plus-maze as a measure of anxiety in the rat. Journal of Neuroscience Methods, 14, 149-167.

Polston, J. E., Rubbinaccio, H. Y., Morra, J. T., Sell, E. M., \& Glick, S. D. (2011). Music and methamphetamine: conditioned cue-induced increases in locomotor activity and dopamine release in rats. Pharmacology, Biochemistry, and Behavior, 98, 54-61.

Pooler, A. M., Xi, S. C., \& Wurtman, R. J. (2006). The 3-hydroxy3-methylglutaryl co-enzyme A reductase inhibitor pravastatin enhances neurite outgrowth in hippocampal neurons. Journal of Neurochemistry, 97, 716-723.

Prut, L., \& Belzung, C. (2003). The open field as a paradigm to measure the effects of drugs on anxiety-like behaviors: a review. European Journal of Pharmacology, 463, 3-33.

Raglio, A., Bellelli, G., Mazzola, P., Bellandi, D., Giovagnoli, A. R., Farina, E., Stramba-Badiale, M., Gentile, S., Gianelli, M. V., Ubezio, M. C., Zanetti, O., \& Trabucchi, M. (2012). Music, music therapy and dementia: a review of literature and the recommendations of the Italian Psychogeriatric Association. Maturitas, 72, 305-310.

RiazaBermudo-Soriano, C., Perez-Rodriguez, M.M., VaqueroLorenzo, C., \& Baca-Garcia, E. (2012). New perspectives in glutamate and anxiety. Pharmacology, Biochemistry, and Behavior, $100,752-774$.

Roecker, R., Junges, G. M., Lima, D. D., Delwing, F., Wyse, A. T., Cruz, J. N., Dal Magro, D., \& Cruz, J. G. (2012). Prolonged acetylcholinesterase inhibition and impairment in object recognition memory in rats subjected to chronic hyperprolinemia. Biology and Medicine, 4, 123-133.

Ruusuvirta, T., Koivisto, K., Wikgren, J., \& Astikainen, P. (2007). Processing of melodic contours in urethane-anaesthetized rats. European Journal of Neuroscience, 26, 701-703.

Santos, T., Baungratz, M. M., Haskel, S. P., de Lima, D. D., da Cruz, J. N., Magro, D. D., \& da Cruz, J. G. (2012). Behavioral interactions of simvastatin and fluoxetine in tests of anxiety and depression. Neuropsychiatric Disease and Treatment, 8, 413-422.
Schoonjans, K., Peinado-Onsurbe, J., Fruchart, J. C., Tailleux, A., Fiévet, C., \& Auwerx, J. (1999). 3-Hydroxy-3-methylglutaryl CoA reductase inhibitors reduce serum triglyceride levels through modulation of apolipoprotein C-III and lipoprotein lipase. Federation of European Biochemical Societies, 452, 160-164.

Sett, A. K., Robinson, T. G., \& Mistri, A. K. (2011). Current status of statin therapy for stroke prevention. Expert Review of Cardiovascular Therapy, 9, 1305-1314.

Sierra, S., Ramos, M. C., Molina, P., Esteo, C., Vázquez, J. A., \& Burgos, J.S. (2011). Statins as neuroprotectants: a comparative in vitro study of lipophilicity, blood-brain-barrier penetration, lowering of brain cholesterol, and decrease of neuron cell death. Journal of Alzheimer's Disease, 23, 307-318.

Swindle, J. P., Potash, J., Kulakodlu, M., Kuznik, A., \& Buikema, A. (2011). Drug utilization patterns and cardiovascular outcomes in elderly patients newly initiated on atorvastatin or simvastatin. American Journal of Geriatric Pharmacotherapy, 9, 471-482.

Toro, J. M., Trobalon, J. B., \& Sebastián-Gallés, N. (2005). Effects of backward speech and speaker variability in language discrimination by rats. Journal of Experimental Psychology: Animal Behavior Processes, 31, 95-100.

Tramontina, A. C., Wartchow, K. M., Rodrigues, L., Biasibetti, R., Quincozes-Santos, A., Bobermin, L., Tramontina, F., \& Gonçalves, C. A. (2011). The neuroprotective effect of two statins: simvastatin and pravastatin on a streptozotocin-induced model of Alzheimer's disease in rats. Journal of Neural Transmission, 118, 1641-1649.

Urban, P., Pavlíková, M., Sivonová, M., Kaplán, P., Tatarková, Z., Kaminska, B., \& Lehotský, J. (2009). Molecular analysis of endoplasmic reticulum stress response after global forebrain ischemia/reperfusion in rats: effect of neuroprotectant simvastatin. Cellular and Molecular Neurobiology, 29, 181-192.

Vaughan, C. J. (2003). Prevention of stroke and dementia with statins: effects beyond lipid lowering. American Journal of Cardiology, 91, 23B-29B.

Wan, C. Y., Demaine, K., Zipse, L., Norton, A., \& Schlaug, G. (2010). From music making to speaking: engaging the mirror neuron system in autism. Brain Research Bulletin, 82, 161-168.

Wang, Q., Zengin, A., Deng, C., Li, Y., Newell, K. A., Yang, G.Y., Lu, Y., Wilder-Smith, E. P., Zhao, H., \& Huang, X. F. (2009). High dose of simvastatin induces hyperlocomotive and anxiolytic-like activities: the association with the up-regulation of NMDA receptor binding in the rat brain. Experimental Neurology, 216, 132-138.

Wu, H., Lu, D., Jiang, H., Xiong, Y., Qu, C., Li, B., Mahmood, A., Zhou, D., \& Chopp, M. (2008). Simvastatin-mediated upregulation of VEGF and BDNF, activation of the PI3K/Akt pathway, and increase of neurogenesis are associated with therapeutic improvement after traumatic brain injury. Journal of Neurotrauma, $25,130-139$

Xu, J., Yu, L., Cai, R., Zhang, J., \& Sun, X. (2009). Early auditory enrichment with music enhances auditory discrimination learning and alters NR2B protein expression in rat auditory cortex. Behavioural Brain Research, 196, 49-54.

Yan, J., Xu, Y., Zhu, C., Zhang, L., Wu, A., Yang, Y., Xiong, Z., Deng, C., Huang, X., Yenari, M. A., Yangs, Y., Ying, W., \& Wang, Q. (2011). Simvastatin prevents dopaminergic neurodegeneration in experimental parkinsonian models: the association with antiinflammatory responses. PLoS One, 6, e20945.

Young-Xu, Y., Chan, K. A., Liao, J. K., Ravid, S., \& Blatt, C. M. (2003). Long-term statin use and psychological well-being. Journal of the American College of Cardiology, 42, 690-697.

Zhang, X., Tao, Y., Troiani, L., \& Markovic-Plese, S. (2011). Simvastatin inhibits IFN regulatory factor 4 expression and Th17 cell differentiation in CD4 $+\mathrm{T}$ cells derived from patients with multiple sclerosis. Journal of Immunology, 187, 3431-3437. 